\title{
Editorial:
}

\section{Clarity and Insights into Educational Debates}

Dolana Mogadime

Editor

Brock University

The publications in this issue of Brock Education Journal provide us, the reader, with clarity and insight into educational debates of importance in our contemporary times. While the questions they raise are of a pressing nature, the concerns come out of issues that are enduring. For example, Ron S. Phillips in "Let's Not Call in the lawyers: Using the Canadian Human Rights Tribunal Decision in First Nations Education," assists readers in facing the role the Government of Canada has played (over decades) in underserving Indigenous children. At the onset of his article, Phillips features the 2016 findings from the Canadian Human Rights Tribunal regarding "the Child and Family services available to First Nations children and families on reserve" (CHRT, 2016, p. 20). Phillips' article provides a careful examination of factors that contributed to the Canadian Human Rights Tribunal decision, specifying that the Government of Canada has discriminated against First Nations students due to their race. Phillips' work illuminates our responsibilities as educators to better know and understand the systemic issues that undercut the quality of education that First Nations students receive. He writes, "It is time to provide First Nations students on reserves a comprehensive system of education." Our attention toward redressing the issues Phillips raises are of paramount importance.

Shelley Stagg Peterson and Dianne Riehl contribution, "Rhetorics of Play in Kindergarten Programs in an Era of Accountability," is informed by the coauthors personal professional experiences in the 1980s teaching in kindergarten settings. They argue that the contemporary interpretation of play as an integral part of learning in kindergarten classes, in some cases, falls short or doesn't match prior understanding. They state, "it appears that the new play-based kindergarten program is being implemented within an environment of uncertainty about play-based learning among teachers." Stagg Peterson and Riehl apply their knowledge of the field by undergoing an investigation of kindergarten program documents that use play as a reference point for three rhetorics of play. As they explain, "we found these three rhetorics of play have been more influential in the development of Ontario kindergartens than the others: (a) The rhetoric of play as progress; (b) The rhetoric of the self and; (c) the rhetoric of identity." Stagg Peterson and Riehl's text analysis of Ontario Ministry of Education documents on kindergarten programs spanning from 1944 - 2010/11 provides much-needed clarity and insight into the debates regarding "accountability-oriented perspectives on kindergarten pedagogies" versus "an understanding of play and its role in children's learning and well-being." Stagg Peterson and Riehl provide further suggestions for teacher education institutions for supporting the preparation of kindergarten teachers toward understanding the complexities of play pedagogies. Audiences for their work include educators, administrators and policy-makers who are seeking a historical analysis and understanding that informs these debates.

Monica McGlynn-Stewart's research on "How Early Childhood Learning Influences Beginning Literacy Teachers' Professional Learning," adds to the debate about "best methods to prepare and support teachers." McGlynn-Stewart reports on a study she conducted with six (out of a larger group of twenty-two) beginning teachers. The research questions guiding the study 
were twofold: "a. How do beginning teachers draw on their early experiences at home and as pupils in their work as teachers?" and "b. How does the relative ease with which they learned literacy as children relate to the way in which they approach learning about teaching literacy as beginning teachers?" Nine key findings from the study are provided however the most illuminating point was "that all of the participants found their pre-service literacy program to have insufficiently prepared them for classroom teaching, and their in-service learning to be more practical and effective." McGlynn-Stewart's study augments the same finding advanced by the Canadian Language and Literacy Research Network, namely that teacher education programs fall short on preparing beginning teachers to teach literacy effectively. McGlynn-Stewart's study is an important read as it extends the discussion of these limitations while providing practical suggestions and possible solutions to the dilemma. One such useful suggestion is that teacher education institutions, "need to differentiate our teaching to meet the needs of pre-service teachers just as we strive to do for school children." McGlynn-Stewart has several useful insights that contribute to the debate regarding best methods for effective literacy teacher preparation within teacher education programs. Tara-Lynn Scheffel's research article, "Individual Paths to literacy Engagement: Three Narratives Revisited" sets out to do what many academics would likely enjoy: she revisits her doctoral research to achieve a greater understanding of the questions which she raised and deeper insights from participants who in 2007 were in Grade 2. Six years later, upon her return, they were in Grade 8.

Scheffel shares the 2 phase (quantitative and qualitative) experimental research methods approach utilized in 2007 that integrated ethnographic classroom observations, individual interviews and parent surveys. Scheffel's revisited research successfully offers an expanded understanding of student engagement within classroom life. She reconnects with three students Spike, Jasper and Avery to draw from student-centered insights that allow her to revise her framework from a focus on literacy and engagement to consideration of a broader "Framework for Engagement" across learning contexts. Documenting her more nuanced focus on students' individual path to engagement she advances the notion that a greater focus on relationships between students and teachers is needed. She explains, “In light of Spike, Jasper and Avery's journeys, teachers were reminded to get to know their students and what contributes to their success in learning." The findings from Tara-Lynn Scheffel's follow-up study advance this important student-centered understanding in relation to the popular topic about student engagement.

Lee Anne Block and Paul Betts in, "Cultivating Agentic Teacher Identities in the Field of a Teacher Education Program" report on their ongoing research on an innovative after degree teacher education program. At the center of the program are principles of collaborative learning and student agency within the process of nurturing teacher identity. Their research on the program is informed by the notion that teacher identity is constructed, complex and negotiated within links between theory and practice. As they explain, "we are interested in the experiences of our teacher candidates, as they participate in layered contexts of the program." They argue that as students reflect and collaborate across these nestled contexts (university course work, school practicum experience) and school-based professional learning meetings (PLM) they "construct a practice that shapes a teacher identity." The article is part of Block and Betts' research program focused on data from the two-year program. Together, the five articles in this issue are useful in providing research, thinking and direction on issues that are challenging educators in both K-12 schools and university settings. 